\title{
The invisible supporters
}

\section{Writing for reuse}

\author{
Eva-Maria Jakobs \& Claas Digmayer \\ RWTH Aachen University
}

This article examines how written feedback is used to support the production of texts for purposes of reuse. The case study refers to an entrepreneur training program at the University of Texas at Austin. In the program, Korean startups are trained in understanding the US market, and developing pitches that convince US investors. They are supported by Quicklook ${ }^{\circ}$ reports. A Quicklook report delivers snapshots of the market receptivity for the startup's product. Market analysts write the reports. In the final stage of drafting, program staff members supervise the report author. This study investigates how supervisors use commenting and how the goal of creating a highly reusable text source guides the feedback process. The database was examined quantitatively (frequency of drafting and commenting) and qualitatively (functional comment types). The results offer valuable insights into actual writing processes in business settings and how professionals interact to ensure a reusable product. The findings indicate a broad range of comment functions. Overall, we distinguish two main categories: feedback activities focusing on Quicklook reports as reusable resource, and feedback activities focusing on collaboration and workflow. Each category includes functional comment types. Further research is needed to learn more about professional strategies of reflecting on text quality, the quality of assessments, or the ratio between detected and real deficiencies of a document.

Keywords: writing and text reuse in business-related environments, entrepreneurship communication, commenting activities, functional feedback types 


\section{Introduction}

Text reuse is a widespread practice of text production in business-related contexts. Written communication is part of complex activities such as creating added value, organizing, regulating, and supporting work, building relationships between departments, companies, and customers, the market and competitors, or documenting products. As with other activities, text productive activities must be efficient and effective (Jakobs \& Spinuzzi, 2014a). Text reuse meets these requirements and is therefore applied frequently. A success-relevant factor concerns the quality of the text resource. Incorrect or inferior text sources can cause significant economic damage. That is why process components that improve the quality of text sources are relevant. Interest in text quality increases if the source document serves as input for documents that are highly important for the implementation of business interests.

So far, there are hardly any linguistic studies that examine how organizations manage to produce high-quality documents for purposes of reuse, e.g., which strategies they use, and how they ensure that the created document supports on a high level the target text production that motivates the creation of the text source. Primarily in the 1990s, some studies emerged that examine strategies in business contexts that help to improve the quality of the text production process or the text product. These studies focus on standard cases of text production in companies and organizations (e.g., writing reports) and strategies such as reviewing and commenting, e.g., as part of document cycles or collaborative writing. Few studies deal with writing documents for reuse and the overall goal of creating a highly reusable document that meets the professional needs of the end user (and their follow-up activities).

We examine these questions in a real-life writing case study. The study is embedded in the domain of entrepreneur communication. Technology innovators must pitch their technology and its business value to potential buyers, partners, and distributors (Jakobs, Spinuzzi, Digmayer, \& Pogue, 2015). To succeed, the invention must be appropriately communicated to a market and iterated through dialogue with potential stakeholders (Spinuzzi, Jakobs, \& Pogue, 2016). Foreign startups, in particular, who are trying to enter an unfamiliar market need help with this. They must deal with a broad range of challenges including a deeper understanding of market needs, values, and cultural expectations. The case study refers to a program that supports foreign entrepreneurs by offering market reports. The market reports are written by contracted market analysts. During the text production process, program staff members supervise them. The overall aim is to create a highly professional report that can be used by the innovator to create a convincing, well-argued pitch that reuses parts of the report - verbatim or in close phrasing (Spinuzzi et al., 2015). From the entrepreneur's point of view, the quality of the 
market report is decisive for the success of his pitch. This study investigates how the supervisors use feedback activities (commenting) to support the report author, and how the overall target to create a highly reusable text source that fulfills professional requirements of the end user and follow-up activities, guides the feedback process. The study is based on a first exploratory study (Jakobs et al., 2015) based on a small sample of the whole data basis. The main interest of this study is to get broader insights on the professional interaction of supervisor and report author.

\section{The case study}

The data used in this paper are part of a larger data set collected by Clay Spinuzzi and Gregory Pogue in the Gyeonggi Innovation Program (GIP), an entrepreneurship program formed by a partnership between the University of Texas at Austin and the Gyeonggi-Do Province in South Korea (Spinuzzi et al., 2014). The GIP offers Korean entrepreneurs interactive trainings, mentorship, and business competition experience. It helps them to develop a better understanding of the US market and - based on this - to improve and hone their pitches (for a detailed description see Spinuzzi et al., 2015, p. 47f.).

The participants learn to understand the new, unfamiliar market. The program supports them by services, such as the Quicklook report. Quicklook is a market assessment methodology. It delivers snapshots of a market's receptivity for a new idea, process, or service (Zehner \& Pletcher, 2017). The GIP contracts market analysts to gather feedback from potential stakeholders in target markets by interviewing them, then write Quicklook reports to summarize and present the results. The Quicklook assessors examine technologies for commercial viability and determine the best commercialization strategies for technologies. Finally, they write a report with market and strategy recommendations. The challenge is to deliver a concise and informative presentation of findings and recommendations.

The assessors are experienced in Quicklook research and composition. In a mature phase of the writing process, they receive feedback from one or more GIP staff members, who comment on the drafts until an acceptable version can be released to the entrepreneurs. Both assessor and supervisor have a professional background in business-related fields and expertise in their respective fields. Their overall aim is to create a highly professional report that can be used by the innovator to create a convincing, well-argued pitch reusing parts of the report - verbatim or in close phrasing (Spinuzzi et al., 2015). 


\section{Literature review}

This article discusses the writing and reuse of texts as domain-specific activities in business-related environments, focusing on entrepreneur communication. Domain-specific discourse communities are characterized by value systems and communicative expectations, conventions and patterns (Jakobs \& Spinuzzi, 2014a). They represent communities of practice shaped by professional cultures and patterns for professional behavior as well as by economic constraints. In business-related contexts, written communication is part of complex activities such as creating added value, organizing, regulating, supporting work, building relationships between company and customer, or documenting products. Like other activities, writing must be efficient and effective. The reuse of texts fulfills these requirements. In many work environments, writing skills involve the ability to create texts by reusing text sources, and/or to produce texts that are reusable (Spinuzzi, 2010; Jakobs \& Spinuzzi, 2014b).

The practical motives of reuse are highly diverse, as well as related linguistic practices. In contrast to other domains, e.g., science and journalism (e.g., Jakobs, 1999; Haapanen \& Perrin, 2018), text reuse in business-related contexts is a lessinvestigated topic. The functions and practices of reuse seems to vary depending on the given sociocultural and socioeconomic framework and other factors, e.g., the industry, the given task, and target criteria (Jakobs \& Spinuzzi, 2014b; Jakobs, 2018). In the case of standard tasks and to meet the general goal of reducing costs, text reuse is becoming increasingly automated. Examples are AI-based methods of extracting and composing information from database content (texts) (Klewes, Popp, \& Rost-Hein, 2017), or the automated reuse of the same source content in different forms of media and genres (single source text production/publishing). Swartz (2009) criticizes that single-sourcing models and derivative technologies cast reusable content as context-less and rhetorically neutral, a perspective that overlooks the underlying rhetorical strategies of reuse. Kendall Roundtree (2017) emphasizes that both the writer of source texts as well as team members of singlesource projects (technical writers, information designers) must have a mastery of writing skills as well as technological and rhetorical skills to ensure a good result.

In many work environments, human writing means writing from text sources. Digital workstations allow access to a variety of digital sources. In an ethnographic study, Leijten et al. (2014) describe in detail how a communication designer creates a proposal over days by using and integrating multiple digital sources. The author integrates parts of existing texts into his own text product by recombining, paraphrasing, and elaborating on them. Another example of reuse occurs in professional document cycles (for an overview see Jakobs and Spinuzzi, 2014b). The reuse of existing documents enables writers to build on solutions 
embedded in previous documents, to increase coherence and accountability, and to circulate information to different parts of the organization (Spinuzzi et al., 2015). During the cycle, experts transform their documents by recombining and transforming information. They integrate parts of other texts verbatim or transformational, and, by doing so, they make rhetorical choices. Transformational reuse typically happens during document cycles in which different actors progressively revise information (Jakobs \& Spinuzzi, 2014b).

Our focus is on text reuse in entrepreneur communication. Entrepreneur communication is a little-investigated topic (for an overview, see Spinuzzi, 2017). Some studies investigate how startups learn to understand their markets and create successful pitches (Spinuzzi, Jakobs, \& Pogue, 2016; Spinuzzi, 2017). Entrepreneurs must be able to pitch their product to different audiences, e.g., to potential buyers, partners, and distributors (Jakobs et al., 2015), and, by doing so, fit to their expectations. This requires considerable communication efforts and skills, e.g., to understand the societal environment and milieu (Jakobs \& Spinuzzi, 2014b), including language and culture: "the meanings, values, and behaviors that groups of people develop and share over time as well as the tangible manifestations of a way of life" (Sun, 2012:460). Innovators are expected to make claims that create interest in the appropriate audiences and offer evidence that those audiences recognize as credible and applicable. Foreign startups must deal with a broad range of challenges, including gaining a deeper understanding of market needs, values, and cultural expectations. The most challenging part is to produce pitches with the structure, claims, evidence, and engagement strategies expected by stakeholders of the target market.

Spinuzzi et al. (2014) studied the process of developing pitch decks in the GIP program. They describe the process of creating and improving the pitch as a full cycle of activities that combines the writing and reading of documents with an ongoing dialogue amongst the involved persons - entrepreneur, mentor, and contracted market analysts. The document cycle includes different genres, such as initial and revised pitches, verbal feedback, and the Quicklook. The entrepreneurs use the feedback to refine their pitches for the potential market (Spinuzzi et al., 2014). By doing so, they improve not only their presentation, they also learn to understand conventions as responses to specific rhetorical exigencies.

Part of the pitch development is the reuse of documents provided by the program. Spinuzzi et al. (2015) analyze how sources are reused to improve the pitches. For this purpose, they examined qualitatively an archive of pitches and related documents and contextualized the process with interviews of program personnel. In their paper, they describe three reuse strategies: 
- Accepting: Accepting means reusing content with little or no change. The reusing person repeats parts of the text source verbatim or in close paraphrase. The strategy is less complex than the other two, but the most widely used one. An often-reused genre is the Quicklook report. The participants mainly paraphrased the information provided here: all investigated entrepreneur teams "paraphrased text from the Quicklook - typically quotes from people representing the target market or the Quicklook author's characterization of that market" (Spinuzzi et al., 2015, p.59).

- Continuing: Continuing means extending lines of arguments. It represents a more rhetorically sophisticated reuse strategy than Accepting. Many entrepreneur teams started with little evidence about whether their product could succeed. The Quicklook offered them remarkable information and help. The Quicklook authors not only investigated the target market, they also interviewed and examined potential buyers, partners, and competitors, and summarized the outcomes in the report. The report offers quotes from interested parties; and describes the opportunities and threats that each entrepreneur team faced when entering the target market. The entrepreneur teams reused this information in different ways, e.g., by simply recapitulating it. But they also extended it, e.g., by developing claims of the author.

- Resisting: The entrepreneurs rebut lines of arguments. Spinuzzi et al. (2015, p.61) describe this as 'mitigation' - "an argument that concedes and minimizes the impact of negative claims against the product or its disadvantages." Some entrepreneurs were not willing to share conclusions of the report. They solved the problem inventively and, by doing so, demonstrated "an ability to engage in critical dialogue with the stakeholders."

To sum up, the startups reuse the content of other sources, in particular the Quicklook report, to prove, extend, enrich, and/or refine the pitch based on the market report.

This article examines how GIP supervisors support the creation of Quicklook reports by providing feedback to the authors. Giving feedback is a frequently studied topic in studies on the interrelation of learning and writing. It is increasingly seen as a competence-related activity (Schindler, 2013). Feedback requires assessment skills including linguistic and thematic competence, social skills, and motivational readiness. A main precondition is that the involved partners are willing and motivated to cooperate. Giving and receiving feedback is a socially shaped process based on qualities such as trust and respectful behavior.

Giving feedback is a cognitive activity; the results have to be linguistically externalized. In this perspective, commenting relates to language in two ways: It "focuses on language and textual phenomena in the draft (...), and is itself a communicative activity expressed through language" (Beyer, 2018, p.15). The feedback 
must be clear. A substantial step is to establish a common perception framework (Schindler, 2013), e.g., by clarifying the scope of the feedback (e.g., entire text, paragraph, sentence), by localizing the feedback, and by choosing a text property (e.g., content, text organization, language quality).

In a study with subject-matter experts and student peers, Cho, Schunn, and Craney (2006) investigate how the type of comment relates to its perceived usefulness. The paper offers an overview on comment typologies. Most typologies are based on the scope of the comment (local vs. global), the topic (mechanics, organization, content), and the function (evaluation, suggestion, response). Important factors seem to be the specificity and directiveness of comments. Cho et al. (2006, 269) distinguish six categories:

- Directive comments: They suggest a specific change.

- Nondirective comments: They suggest a nonspecific change (that can apply to any paper).

- Praise: The comment gives a positive feedback to the text or portions of the text, e.g., by encouraging remarks.

- Criticism: The comments give a critical or negative feedback without suggestions for improvement.

- Summary: The comment recapitulates the main points.

- Off-task: The comment does not fit any of the other categories.

Their results show that directive comments and praise influence the perceived helpfulness positively. Subject-matter experts who give feedback prefer directive comments that specify exactly how to resolve problems. Their comments are longer than the comments provided by student peers.

Alvarez, Espasa, and Guach (2011) stress that the form of feedback matters. When teacher feedback includes suggestions and questions, instead of direct corrections, the students respond more constructively, discuss the content they are working on with more intensity, and create more significant changes in the arguments of the text they are revising (see also Guasch, Espasa, \& MartinezMelo, 2019).

In the research field 'writing at work', feedback activities are discussed as inherent part of collaborative writing, revision making, and document cycles with feedback-giving entities (Paradies, Dobrin, \& Miller, 1985; for an overview on revisions in document cycling Spinuzzi et al., 2015). A basic assumption is that the actors involved are professionally motivated to cooperate and that they are capable to provide helpful comments.

How a professional document is commented on depends on different factors, e.g., the degrees of freedom. In high-risk domains, commenting in document cycles is formal, highly regulated, and controlled (Sauer, 2003). In less restricted domains, 
feedback can be rapid, informal, flexible, and creative (Spinuzzi, 2010). Kleimann (1993) reports that the number and mode of comments differ depending on the work culture of a company. In less-hierarchical contexts, reviewing serves as collaborative negotiation process and as a chance to share knowledge and to learn from each other; commenting serves as problem-solving mean (more content-related comments, more questions). In more-hierarchical contexts, reviewing tends to be seen as a hierarchical requirement; the comments address more language-related issues. In organizations, commenting on a colleague's writing serves as a form of quality control that is essential to creating a document that meets multiple organizational needs (Brand, 2005). Controversial issues often concern stylistic choices (Schindler \& Wolfe, 2014). However, conflict over content and rhetorical issues seems to be highly productive. It fosters rethinking argumentation from multiple perspectives and trying out alternative solutions to problems (Wolfe, 2010).

To our knowledge, no study investigates how feedback activities are used professionally to enhance the production of texts for purposes of reuse (but see Jakobs et al., 2015). Jakobs et al. (2015) investigate the topic from the perspective of entrepreneur communication and the concept 'co-creation of value and knowledge' based on a small sample of the GIP entrepreneur program data set (24 Quicklook reports). The terms co-creation of value and co-creation of knowledge refer to more spontaneous, collaborative, and dialogical interactions, where putting things together that others do not think go together achieves something new and unique in the process and leads to competitive advantage (London, Pogue, \& Spinuzzi, 2015; Ballantyne \& Varey, 2006). The results of Jakobs et al. (2015) indicate that commenting is used as participatory way to create meaningful content. Nearly all reports underwent a revision cycle. The authors distinguish four main functional comment types: (1) Comments related to co-creation. They focus on the content and the function of Quicklook to help innovators to understand the market needs with respect to the innovator's idea (product, process, or service). (2) Comments related to argumentation: This type focuses on rhetorical issues and the function of Quicklook to enhance the innovator's pitch. (3) Comments related to the writing process: They focus on the further report-production process, e.g., the organization of the next steps. (4) Comments related to the text quality: They refer to the overall text quality of the report as well as to certain composition levels. Types 1 and 2 are used to enhance the recommendation quality, while types 3 and 4 aim to increase the comprehensibility. 


\section{Research methodology}

\section{Data collection}

The study uses data from the GIP training program archive. The data basis investigated comprises 139 data sets (1027 document files) created between 2008 and 2013. A data set or case includes all (commented) drafts of a particular Quicklook report cycled between supervisor and author. Each Quicklook report is presented under the name of its assessor alone. The data basis does not include communications beyond the comments in the drafts (e.g., documented phone calls, emails, or activities in the shared groupware system).

\section{Data preparation}

The data preparation included seven steps: (1) The drafts of the 139 Quicklook sets were ordered according to the date of creation and the title of the proposal as stated in the proposal. Corrupted document files $(n=382)$ were deleted (remaining corpus: 138 data sets, 645 document files). (2) A software program was developed on basis of the Jsoup library to extract comments and comment-related information: the initials of the commentator name; the comment anker, or the part of a document to which the comment refers; the title of the commented section; and the file name of the text in which the comment occurs. To operate the software, the word files were converted into HTML files. (3) The documents were checked manually to ensure that all comments were identified. If a document was commented in other ways than by using the commenting function in Microsoft Word (e.g., integrated in the report text), the comments were marked (documents, $n=11$; comments, $n=58$ ). (4) All comments $(n=3063)$ were extracted, enriched with metadata, and exported into an Excel file. (5) The corpus was checked manually to detect and delete duplicates (comments that were transferred from one draft to the other; $n=963$ ) as well as "empty" comments $(n=22)$. (6) The final data set $(n=2100$ comments) was checked manually to ensure a high level of data quality. (7) The section titles were checked for consistency in naming.

\section{Data analysis}

The dataset was analyzed quantitatively and qualitatively. In the following we describe both approaches. 


\section{Quantitative analysis}

To get an overall understanding of the feedback procedure provided by the GIP over six years, we investigated four aspects of the drafting process: The number of feedback providers, the number of feedback loops per case, the frequency of commenting per draft, and the frequency of commenting per document structure part. The first aspect was to estimate the level of expertise that is required to create the Quicklook documents. The second and the third aspects were an analyses of the estimated effort necessary to create documents that are suitable for reuse purposes. It is assumed that Quicklook creation needs to be processed carefully, which presupposes multiple revisions and various comments as input for such revisions. The fourth aspect we examined was which document parts are the focus of the revisions. It is assumed that not all structural parts of the Quicklook documents receive the same amount of attention during revisions but only those that have the most value for reuse purposes.

\section{Qualitative analysis}

The qualitative analysis aims to understand how program supervisors use feedback activities functionally to support the creation of high-quality documents that are written for purposes of reuse and reuse strategies (Spinuzzi et al., 2015). Step 1 was a content analysis. Similar to Jakobs et al. (2015), the comments of the revised data set were viewed from two perspectives - the reference perspective (e.g., referring to linguistic text quality) and the comment function (e.g., drawing the author's attention to missing content). The results are described as (functional) comment types. In a second step, the linguistic form of the comments was analyzed based on the typology of Cho et al. (2006).

\section{Quantitative results}

The quantitative analysis examines four aspects of the commenting process: The number of feedback providers, the number of feedback loops per case, the frequency of commenting per draft, and the frequency of commenting per document structure part. In the following, the quantitative results are described and discussed for each examined aspect. The results relate to the revised data set (138 report cases, 656 documents, 2100 comments). 
Number of feedback providers

In the six years examined, 31 GIP staff members actively provided feedback. The number of commenters per document varies between one and four (see Figure 1). Mostly, the documents were commented on by one expert (53.41\%) or two experts (35.23\%); on average, each document included comments from 1.6 experts. Documents with three $(9.09 \%)$ or four experts $(2.27 \%)$ are rather uncommon. The data indicate that in many cases more than one GIP supervisor was necessary. The contents of the comments indicate that such cases occur when the product to be evaluated requires the combined expertise of several fields of knowledge that a single expert does not have at his disposal.

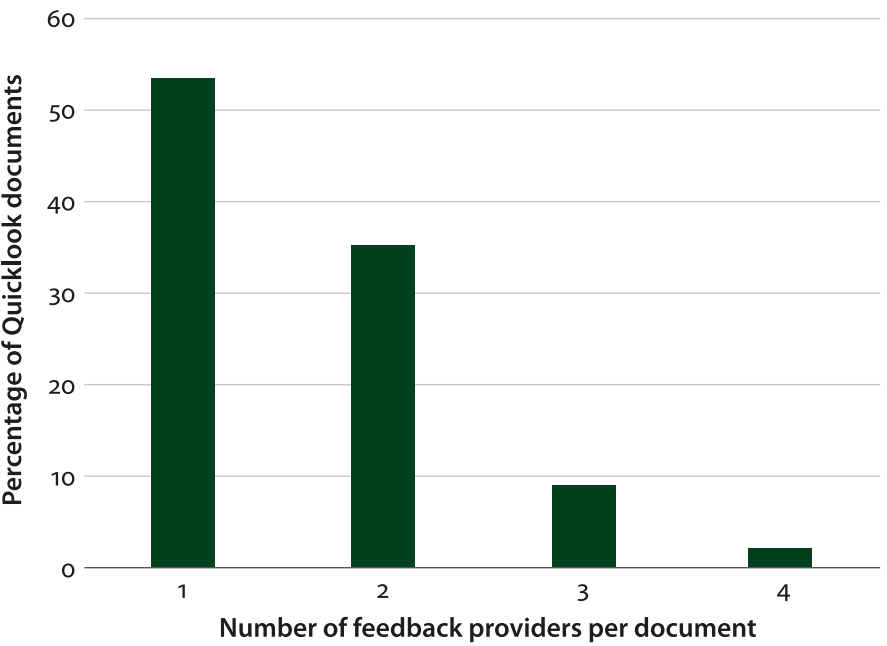

Figure 1. Number of feedback providers per document

Number of feedback loops per case

Jakobs et al. (2015) describe the Quicklook report writing as an iterative production process characterized by an intensive professional collaboration between report author and supervisor. What does 'iterative' and 'intensive' mean with respect to our case study? The analysis of the data set shows that $92.59 \%$ of the cases (125 of the 138) underwent a document cycle. The number of drafts per data set varies between 1 and 10 (on average $=4,7$ ). Two thirds of the cases are commented verbally ( $n=93 ; 520$ documents). The number of drafts per data set varies here between one and ten (on average $=5,6$ ). 
Frequency of commenting per draft

We analyzed only cases with written comments. The frequency of commenting differs strongly per document (on average $=13,98$ ). Some cases contained only one comment; in other cases, the need for optimization seemed to be very high - up to 83 comments (Figure 2).

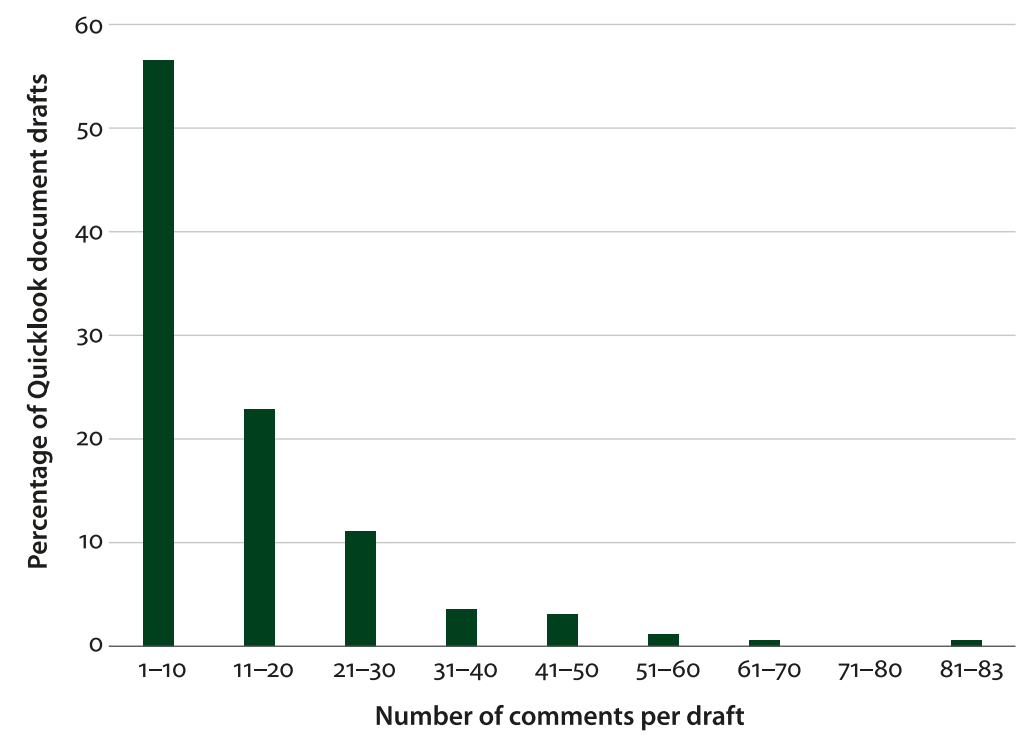

Figure 2. Frequency of commenting per draft

In $92.05 \%$ of all cases, the first draft is commented frequently, while the number of comments in later drafts decreases. It seems that after a first phase of intensive corrections the most important problems in the drafts have been resolved, and only minor corrections are necessary in later drafts. This is not surprising insofar as giving feedback starts in a mature phase of the report writing process. A small percentage of cases (7.95\%) show a different picture: The number of comments increases from first to later drafts. This can be explained by the quality of the first drafts, which are in a rough and preliminary state. Comments in these first stages are mainly directional, indicating what is missing and organizing next steps. 
Frequency of commenting per document structure part

The Quicklook report provides guidance by a predefined structure and section titles. In general, the authors report adheres to the structure specifications. Sometimes headings are slightly varied (e.g., "Development Status" versus "Status"), or new ones are added (e.g., "Appendix Three: Intellectual Property"). These aspects were taken into account during the analysis.

The results of the analysis of the revised data set show that - in contrast to Jakobs et al. (2015) - all parts of the report contain comments (see Table 1). The most frequently commented sections are: Potential Commercial Markets; Potential Benefits; Competitors and Competing Technologies; Technology Description; Appendix One: Interview Notes; and Executive Summary. They provide particularly important information for the startups.

Table 1. Frequency of commented structure parts

\begin{tabular}{lccc}
\hline Section & Rank & Total number & Percent \\
\hline Potential commercial markets & 1 & 349 & 16.62 \\
Potential benefits & 2 & 245 & 11.67 \\
Competitors and competing technologies & 3 & 207 & 9.86 \\
Technology description & 4 & 197 & 9.38 \\
Appendix one: Interview notes & 5 & 187 & 8.90 \\
Executive summary & 6 & 186 & 8.86 \\
Development status & 7 & 162 & 7.71 \\
Potential challenges & 8 & 107 & 5.10 \\
Status of the intellectual property & 9 & 103 & 4.90 \\
Potential opportunities & 10 & 96 & 4.57 \\
Recommendations & 11 & 93 & 4.43 \\
Title & 12 & 66 & 3.14 \\
Next Steps checklist & 13 & 28 & 1.33 \\
The University of... & 14 & 20 & 0.95 \\
Appendices & 15 & 20 & 0.95 \\
Appendix three & 16 & 12 & 0.52 \\
Appendix two: Contact list & 17 & 11 & 0.52 \\
Technology assessment and commercialization report & 18 & 10 & 0.48 \\
Appendix four & & 1 & 0.05 \\
\hline
\end{tabular}


It is rather surprising that the more predefined parts of the overall document structure, such as the title or the heading "The University of...", are in the focus of supervision. Hence, a second analysis step was carried out to examine the content of such comments. The results show that the comments referring such document parts are predominantly used for three purposes: to improve the formulation (e.g., spelling correction); to give general feedback on the overall state of the document; or to update the author about the reviewing process and related activities.

The quantitative results partly confirm findings of Jakobs et al. (2015). In both studies, the three most frequently commented document sections are the same. In contrast to the rather small sample of the first study, the analysis of the data set shows that, in particular, the integration and use of interview notes seems to be important. Interview Notes holds rank 5 of the most frequently commented topics. This is in the logic of the Quicklook Process (Zehner \& Pletcher, 2017). The interview notes document the quintessence of the Quicklook authors' interviews with investors and other relevant market representatives; they deliver the content for the reports.

\section{Qualitative results: Functions of commenting}

Our main interest is to understand how feedback activities are used to create a highquality document that is written for purposes of reuse. In particular, we want to understand if and how the supervisors consider and thematize the requirements and consequences of reuse strategies in their comments (Spinuzzi et al., 2015).

Our results indicate a broad functional spectrum of commenting. Overall, we distinguish two main categories:

- Feedback activities focusing on Quicklook reports as reusable resources;

- Feedback activities focusing on collaboration and workflow.

Each category includes functional comment types. In the following, we describe the categories and related comment types and feedback activities.

\subsection{Feedback activities focusing on Quicklook reports as reusable resources}

The supervisor's activities focus on the report. The overall goal is to ensure a highly reusable Quicklook report that meets the objectives of the addressee. The feedback relates to three object areas - content; argumentation; and text quality (see Table 2). For each area, we identified functional comment types and subtypes. 
Table 2. Feedback activities focusing on Quicklook reports as multiple reusable resource

\begin{tabular}{ll}
\hline Reference direction & Functional comment type \\
\hline $\begin{array}{l}\text { Feedback activities related to } \\
\text { content }\end{array}$ & $\begin{array}{l}\text { Comments co-creating value and knowledge } \\
\text { Comments raising awareness on divergences between } \\
\text { national markets } \\
\text { Feedback activities related to }\end{array}$ \\
$\begin{array}{l}\text { Comments asking for clarification } \\
\text { Comments asking for quantification }\end{array}$ \\
Comments verifying the relevance of information \\
Comments asking for evidence \\
Feedback activities related to the & Comments indicating gaps and failures \\
& Comments improving the structure \\
& Comments improving formulations \\
& Comments improving visual design elements
\end{tabular}

\section{Feedback activities related to content}

Content-related feedback focusses on the function of the Quicklook report, to help innovators to understand the market needs with respect to the innovator's idea. In this context, we identified two comment types: "comments co-creating value and knowledge" and "comments raising awareness on divergences between national markets".

\section{"Comments co-creating value and knowledge"}

Comments co-creating value and knowledge focus - as the name indicates - on the creation of value and knowledge. The comment type requires subject-matter experts with a good knowledge of the technical expert domain and the potential market. In our case study, the supervisors used this type for all relevant topics of the report, e.g., potential commercial markets, or the maturity of the innovation.

(1) There's an incomplete picture being painted here: IC wafer testing probe cards are down to $13.9 \%$ growth rate, memory market probe cards down to only a $3.4 \%$ growth rate this year - so in what segment of the probe card market are they expecting strong growth that will allow the market as a whole to grow $71 \%$ in just four years?

(2) I'm a little confused by this. We say it is developed and in use in Korea, but we have made several references to needing further testing to make sure sanitizing systems works and Ad works. [...] For this report, we want to know whether or not this company's product is fully developed, tested and commercially ready for sale. $[\ldots]$ 
Comment subtypes serve to indicate gaps, to request the report author to do more research, or to think about alternatives. An often-used linguistic form is asking questions, e.g., how to interpret interview results.

(3) Armando, Lots of missing interviews here. Did not find Franklin and Lavalliere.

(4) Did any research uncover the usable life of child furniture? (...) Does the kid go through 3 sets of furniture by the time they are a teenager? This would be a valuable selling point.

\section{"Comments raising awareness on divergences between national markets"}

Highly relevant for foreign innovators is to understand differences between national markets, in particular between their home market and the target market. This includes the perspective of potential investors, partners, and suppliers, competitors, and customers. The comments sensitize the report author to national differences and thematizes these differences as important items for review. They encourage the author to reflect on national differences, often in the form of questions.

(5) Hmm.... Korea's quite cold - does this mean he should do testing further south? Or in Texas? [...]

(6) Do we know the burden of proof they'll need to show for quality? I'd think they'd have that for the Korean market....do you recommend they present that as part of a pitch?

\section{Feedback activities related to argumentation}

Argumentation-related feedback activities focus on "rhetorical issues and the function of the Quicklook to enhance the innovator's pitch" (Jakobs et al., 2015, p.294). We identified five comment types: "asking for clarification"; "asking for quantification"; "verifying the relevance of information"; "asking for evidence"; and "indicating gaps and failures". Our results confirm outcomes of Jakobs et al. (2015). Furthermore, they allow a more complete idea of how the supervisors use feedback to increase the quality of argumentation by qualifying arguments and minimizing weak points.

\section{"Comments asking for clarification"}

Comments asking for clarification are used by the supervisors to support the accessibility of information by a clear, precise, and complete description of the topic. In our study, this comment type is used frequently. The comments help the report author to avoid misunderstandings and to create a reliable argumentation. Need for 
clarification can concern: missing information; the point of reference or topic in question; the description of facts; the scope of a claim; the level of detail; or culturerelated issues (e.g., the unit of measurement). Comments asking for clarification draw the author's attention to text parts that are ambiguous, vague, or in need of interpretation, and/or they can initiate activities to improve these text parts. In these cases, the comment type is interlinked with the comment type "text quality". Partially, the comment is limited to asking for clarification without any clue what should be clarified and why (e.g., Or???).

(7) I'm getting confused with software now. SoftXpand, Microsoft and Linux. This needs some clarification where each fits into the picture.

(8) Fahrenheit? Celsius?

(9) Is this an inferred Yes recommendation? Is so, state that. Otherwise, say no.

\section{"Comments asking for quantification"}

Business-related contexts have a high affinity for numbers and quantification. Potential target groups such as investors and partners want to be able to assess whether the innovation works and is financially promising. They expect facts and evidence that are supported by numbers. A main function of the report is to deliver these numbers.

(10) Any time you can quantify this it adds to the persuasiveness, and anything not quantified softens the doc (...).

\section{"Comments verifying the relevance of information"}

This type aims to ensure that a particular information, topic, or fact is relevant for the report argumentation, by looking how it is contributing to a line of argumentation.

(11) Now that is very interesting!!! Put that up in the competitors section then refer back here.

(12) I think this is secondary. [...]

\section{"Comments asking for evidence"}

All statements in the market analysis must be substantiated. Therefore, an important quality feature is the proof of source. Citations increase the credibility of the argument. The function of this comment type is to display missing references or to request the Quicklook author to add references. In his comment, a GIF expert explains why it is so important to substantiate statements with citations: 
(13) I know I am being very insistent on citations and showing who or where something came from. The reason for that is that [...] the reports will be delivered to each company and somebody from GCG will [...] answer questions. Sometimes they might be challenged on certain points. We want a high degree of citations so whoever is sitting across from the company can refer to "who in the market said that or where the statement came from". [...] we don't want the "facts" in the body of the report to sound like they are simply your opinions.

\section{"Comments indicating gaps and failures"}

The function of this comment type is to ensure the overall argumentative quality by identifying and/or correcting gaps and potential failures in the argumentation, or to draw attention to contradictions in the argumentation.

(14) Ok. 150 per day $=4500$ a month, which is $54 \mathrm{k}$ a year, which is close to $60 \mathrm{k}$ a year (planned expansion) but not close to $20 \mathrm{k}$ a year or month? Something not right here.

(15) Here you say a prototype exists but further down you say it is fully developed and in use.

\section{Feedback related to the text quality}

The text feedback aims to enhance the linguistic text quality, and to make sure that all parts of the Quicklook report can be reused in the phase of pitching development. In our case study, the feedback is mainly used to improve the quality of three text properties: structure, formulations, and visual text design. Structure-related comments support the reuse strategy Continuing; formulation-related comments support the reuse strategy Accepting.

\section{"Comments improving the structure"}

The main function of this comment type is to enhance the text quality by sensitizing the author for structure-related text problems and/or by guiding the revision process by recommendations. The supervisor uses commenting with the overall aim of shaping the content organization by structuring content according to the internal logic of the Quicklook report. The comments help to create and enhance the argumentation lines of the report and, by doing so, support the end user of the report and their reuse strategy. Often, the supervisors explain why the author should move a particular piece of information, number, or argumentation to another section, e.g., because it has an impact on the persuasiveness of this section. Partly, they justify the recommendation by referring to the function of a particular section, and/or to content and information expected there. Only a 
few comments address local structural decisions, such as the use of footnotes or sequencing.

(16) Move to market section.

(17) I think I would summarize the cost benefit here and move the quotes to the market interest section.

(18) Begin this section with, The recommendation of this report would be... [...] Then explain reasoning and rationale for recommendation. [...]

\section{"Comments improving formulations"}

This comment type focuses on text qualities such as clear and precise wording, in particular, terminology, convincing phrases, and style decisions. The supervisors highlight weak formulations. They ask the authors to review formulations, or they suggest formulation alternatives.

(19) Need to check this is the right terminology.

(20) Great sentence construction for our Koreans. SNK has better English skills than many, but our partner there will appreciate your attention to this. Thanks.

\section{"Comments improving visual text design elements"}

The third comment type aims to increase the quality of visual text design elements. The Quicklook report writing is characterized by an intensive use of tables and lists. In particular, lists seem to be a very prominent mean to present information in a structured way. Many comments thematize the use of bullet points. The supervisors recommend adding bullet points; they ask the author to check the use of bullet points; or they criticize the excessive use of bullet points.

(21) Bullets for lists will make it easier for Bizdev guys to scan. Plz bullet!

(22) Honestly, bullet points are very effective is used appropriately, but when the entire report is essentially bullet points, it becomes hard to get a real flow. I would start this section with a brief paragraph, [...]

\subsection{Feedback activities focusing on collaboration and workflows}

In this section, we describe and discuss feedback activities focusing on two relevant facets of the text production process: the collaboration of involved instances and the workflow of the author. Related comment types are shown in Table 3. 
Table 3. Feedback activities focusing on collaboration and workflow

\begin{tabular}{ll}
\hline Reference direction & Functional comment type \\
\hline Feedback activities related to collaboration & Comments serving co-creation \\
& Comments encouraging the author \\
& Comments initiating external support \\
Feedback activities related to the workflow & Comments organizing the next steps \\
& Comments initiating a media switch \\
\hline
\end{tabular}

\section{Feedback activities related to collaboration}

As mentioned earlier, the author and GIP expert(s) collaborate to produce a highquality report. Working collaboratively allows each to profit from the other's strength. It helps the author to master the task of writing a high-quality market analysis in a cooperative way. The collaboration has many faces. It can aim to improve the content, arguments, and text quality or to stimulate the partner and build up a good partnership. In our data, we identified three comment types: comments serving co-creation, comments encouraging the author, and comments initiating external support. They relate to different comment types mentioned earlier (feedback activities focusing on Quicklook reports as multiple reusable resource).

\section{"Comments serving co-creation"}

London et al. (2015) describe co-creation as collaborative, dialogical interactions based on trust. In entrepreneur communication, main targets of co-creation are to create value and knowledge. The comments support the process of co-creating a high-quality market by developing a shared perspective and understanding and/or by encouraging the partner to change perspectives and to rethink topics. Insofar, commenting is part of the meta discourse between supervisor and report author. Cooperation and team orientation are signaled by various means, for example, by using the personal pronoun we (e.g., Can we...), by addressing the partner as person, or by using humor.

(23) This makes sense. They should focus overseas. One thing that is missing but could be beneficial even if they wait $\mathrm{x}$-number of years would be to determine if there are any industry associations that it would be beneficial for them to join. It could give them perhaps some relationships they could begin to develop and with conferences an opportunity to become known to industry people (...).

(24) Frank, the report is in overall good shape but I think we could use some rethinking when we get to this section. As my comments below state. It seems like what we have here or more opinions and criticisms than specific challenges factfully laid out for the innovator to consider. 
(25) Hah! You better watch out. Donna has me helping on reviews too! Remove parentheses.

\section{"Comments encouraging the author"}

The overall aim of commenting is to support the author personally by signaling appreciation for his or her work done. The supervisor thanks the author for the work done, for example, for a text revision. He expresses his satisfaction with a change and/or the current stage of text progression. Comments of praise are often reduced to minimalistic phrases (e.g., Nicely done), partly in combination with a means of reinforcement, such as capital letters or exclamation marks (e.g., GREAT; Great job!). More often, the supervisor explains what he appreciates and why. Commonly, praise is followed by an instruction on how to improve something. In this case, praise can be interpreted too as an attempt to frame or to maintain a positive partner relationship.

(26) Excellent summary of recommendations. Can you just add one example of such a niche market $[\ldots]$ ?

\section{"Comments initiating external support"}

Sometimes the collaboration seems to reach its limits in terms of professional expertise. Then the involved actors need external help. The function of this comment type is to indicate need for additional help and/or to inform the author about ongoing activities and their result. We found manifold traces that both involved parties - supervisor and report author - use a broad network to make progress.

(27) I talked to Donna about how to handle this appendix [...]

(28) I have a UT research looking at this. [...]. He has said next week he will have answers.

\section{Feedback activities related to the workflow}

Commenting is used to organize the work - what has to be done next - and, by doing so, to enhance the progress of the writing process. Two comment types are distinguished in this category: Comments organizing the next steps and comments initiating a media switch.

\section{"Comments organizing the next steps"}

Many comments are geared towards enhancing the workflow. Their main function is to organize the next steps, such as deleting something or doing more research. As in Jakobs et al. (2015), this category is closely interlinked with comments referring 
to content. Often, next steps are formulated as an instruction, recommendation, or question. The instructions can be very short (e.g., Delete.) or can provide detailed directives. In some cases, commenting is used to indicate that a particular work step has been accomplished (e.g., Corrected, Clarified, or Added interview).

(29) Armando, This section will need deeper development than the current version. What is going on in these markets? Are they growing, shrinking? How big are they? What are the trends? [...]

\section{"Comments initiating a media switch"}

When the boundaries of written commenting are reached, the supervisor proposes other forms of exchange. Our data are limited to drafts and written comments. However, the comment analysis indicates that writing and written commenting are part of a multimodal activity space, in which the persons involved interact by using different media and formats, for example personal conversation, phone call, chat, and email. The switch to forms of direct exchange seems to be initiated, in particular, when previous attempts to clarify content have failed or direct clarification seems to be more promising:

(30) You also stated in our phone conversation [...].

(31) I see they are being vague. A quick email, cc me and we'll see if we can't drag it out of them!

\section{Conclusion and outlook}

In this study, text recycling is a functional component of a full cycle of communication activities. All activities support one aim - the creation of pitches based on resources that are written for this purpose. The study investigates how supervisors support the resource production and how the goal of creating a highly reusable text source guides their feedback activities. The results show that the interaction of supervisor and source author is shaped by contextual constraints and by concepts of resource properties that support linguistic text recycling.

The findings confirm the strong impact of domain- and task-related factors. Commenting is embedded in a business-related environment with domain-specific goals, rules, and codes of behavior (Jakobs \& Spinuzzi, 2014b). The involved actors share the same professional goal of creating market reports that help the readers to create successful pitches. They are aware that the report is a highly relevant source for professionals using it and that the report's suitability for reuse strategies is critical for the success of all following activities. The feedback activities go far beyond object-related goals such as quality control and review. Feedback also serves social 
aims such as to encourage the author and to express appreciation for the work done. By doing so, the supervisors act in different roles and build up a working partnership. Directive comments are the most frequently used form.

There is a need for further research to learn more about the strategies experts in business-related contexts use to reflect on the quality of professional documents and the quality of their content-, argumentation-, and/or text surface-related assessments. This includes asking the following questions: Which assessment strategies do they use? Which of these are helpful, and which are not? Which concepts of document quality guide their actions? How do the concepts relate to resource properties that support linguistic down-, cross-, or upcycling?

Another research gap concerns suitable methods for examining extensive corpora. This includes computer-supported tools to identify, extract, and analyze comments quantitatively and qualitatively. A promising approach could be to add text mining methods. Tools such as 'word clouds' would be helpful to detect all occurrences of a particular comment type for a more complete analysis. They require libraries of verbal markers indicating the comment type.

Our analysis is based solely on report drafts and written comments. It would be very interesting to reinterpret the data including interactions between supervisor and author such as meetings or phone calls. Another promising approach, to understand how texts are produced for reuse, would be to extend the research focus on the process of collecting market information by interviews. Further research should broaden our knowledge with regard to other professional settings, interests, and strategies in real-life writing settings (Perrin, 2013).

\section{Acknowledgements}

We thank Clay Spinuzzi and Gregory Pogue for providing the data for the purposes of this study.

\section{References}

Alvarez, I., Espasa, A., \& Guasch, T. (2011). The value of feedback in improving collaborative writing assignments in an online learning environment. Studies in Higher Education, 37(4), 387-400. https://doi.org/10.1080/03075079.2010.510182

Ballantyne, D., \& Varey, R. J. (2006). Creating value-in-use through marketing interaction: The exchange logic of relating, communicating and knowing. Marketing Theory, 6(3), 335-348. https://doi.org/10.1177/1470593106066795

Beyer, K. (2018). InliAnTe: Instrument für die linguistische Analyse von

Textkommentierungen. Linguistik online, 91(4), 15-40. 
Brand, D. (2005). Writing for a living: Literacy and the knowledge economy. Written Communication, 22(2), 166-197. https://doi.org/10.1177/0741088305275218

Cho, K., Schunn, C., \& Charney, D. (2006). Commenting on writing. Typology and perceived helpfulness of comments from novice peer reviewer and subject matter experts. Written Communication, 23(3), 260-294. https://doi.org/10.1177/0741088306289261

Guasch, T., Espasa, A., \& Martinez-Melo, M. (2019). The art of questioning in online learning environments: The potentialities of feedback in writing. Higher Education, 44(1), 111-123.

Haapanen, L., \& Perrin, D. (2018). Media and quoting: Understanding the roles, purposes and processes of quoting in mass and social media. In C. Cotter \& D. Perrin (Eds.), Handbook of language and media (pp. 424-442). London: Routledge.

Jakobs, E.-M. (1999). Textvernetzung in den Wissenschaften. Zitat und Verweis als Ergebnis rezeptiver, reproduktiver und produktiver Prozesse. Tübingen: Niemeyer. https://doi.org/10.1515/9783110945928

Jakobs, E.-M. (2018). Textproduktion und Kontext: Domänenspezifisches Schreiben. In N. Janich (Ed.), Textlinguistik. 15 Einführungen (pp. 255-270). Tübingen: Narr.

Jakobs, E.-M., \& Spinuzzi, C. (2014a). Professional domains: Introduction: Domain specific perspectives in text production research. In E.-M. Jakobs \& D. Perrin (Eds.), Handbook of writing and text production (pp. 325-332). Berlin: De Gruyter Mouton. https://doi.org/10.1515/9783110220674.325

Jakobs, E.-M., \& Spinuzzi, C. (2014b). Professional domains: Writing as creation of economic value. In E.-M. Jakobs \& D. Perrin (Eds.), Handbook of writing and text production (pp. 361-384). Berlin: De Gruyter Mouton. https://doi.org/10.1515/9783110220674.359

Jakobs, E.-M., Spinuzzi, C., Digmayer, C., \& Pogue, G. (2015). Co-creation by commenting: Participatory ways to write Quicklook reports. Proceedings of the IEEE International Professional Communication Conference 2015, 291-297.

Kendall Roundtree, A. (2017). Sizing up single-sourcing: Rhetorical interventions for XML documentation. In A.P. Lamberti \& A.R. Richards (Eds.), Complex worlds: Digital culture, rhetoric and professional communication (pp. 213-234). New York, NY: Routledge.

Kleimann, S. (1993). The reciprocal relationship of workplace culture and review. In R. Spilka (Ed.), Writing in the Workplace: New Research Perspectives (pp. 71-83). Carbondale, IL: Southern Illinois University Press.

Klewes, J., Popp, D., \& Rost-Hein, M. (2017). Out-thinking organizational communications. The impact of digital organization. Berlin: Springer. https://doi.org/10.1007/978-3-319-41845-2

Leijten, M., Van Waes, L., Schriver, K., \& Hayes, J. (2014). Writing in the workplace: Constructing documents using multiple digital sources. Journal of Writing Research, 5(3), 285-337. https://doi.org/10.17239/jowr-2014.05.03.3

London, N., Pogue, G., \& Spinuzzi, C. (2015). Understanding the value proposition as a cocreated claim. Proceedings of the IEEE International Professional Communication Conference 2015, 298-305.

Paradies, J., Dobrin, D., \& Miller, R. (1985). Writing at Exxon ITD: Notes on the writing environment of an R\&D organization. In L. Odell \& D. Goswami (Eds.), Writing in nonacademic settings (pp. 281-307). New York, NY: Guilford.

Perrin, D. (2013). The linguistics of newswriting. Amsterdam: John Benjamins. https://doi.org/10.1075/aals.11

Sauer, B. (2003). The rhetoric of risks. Mahwah, NJ: Lawrence Erlbaum Associates. https://doi.org/10.4324/9781410606815 
Schindler, K. (2013). Texte beurteilen - Feedback geben. Kompetenzen für Lehramtsstudierende. In H. Brandl et al. (Eds.), Mehrsprachig in Wissenschaft und Gesellschaft. Mehrsprachigkeit, Bildungsbeteiligung und Potenziale von Studierenden mit Migrationshintergrund (pp. 57-68). Bielefeld: Zif.

Schindler, K., \& Wolfe, J. (2014). Beyond single authors: Organizational text production as collaborative writing. In E.-M. Jakobs \& D. Perrin (Eds.), Handbook of writing and text production (pp. 159-173). Berlin: De Gruyter Mouton. https://doi.org/10.1515/9783110220674.159

Spinuzzi, C. (2010). Secret sauce and snake oil: Writing monthly reports in a highly contingent environment. Written Communication, 27(4), 363-409. https://doi.org/10.1177/0741088310380518

Spinuzzi, C., Nelson, R.S., Thomson, K.S., Lorenzini, F., French, R.A., Pogue, G., Burback, S.D., \& Momberger, J. (2014). Making the pitch: Examining dialogue and revisions in entrepreneurs' pitch decks. IEEE Transactions on Professional Communication, 57(3), 158-181. https://doi.org/10.1109/TPC.2014.2342354

Spinuzzi, C., Nelson, R.S., Thomson, K.S., Lorenzini, F., French, R.A., \& Pogue, G. (2015). Remaking the pitch: Reuse strategies in entrepreneurs' pitch decks. IEEE Transactions on Professional Communication, 58(1), 45-68. https://doi.org/10.1109/TPC.2015.2415277

Spinuzzi, C., Jakobs, E.-M., \& Pogue, G. (2016). A good idea is not enough: Understanding the challenges of entrepreneurship communication. Proceedings of the 5 th International Conference on Competitive Manufacturing Technologies, 547-552.

Spinuzzi, C. (2017). Introduction to special issue on the rhetoric of entrepreneurship: theories, methodologies, and practices. Journal of Business and Technical Communication, 31(3), 504-507. https://doi.org/10.1177/1050651917695537

Sun, H. (2012). Cross-cultural technology design: Crafting culture-sensitive technology for local users. New York, NU: Oxford University Press. https://doi.org/10.1093/acprof:0so/9780199744763.001.0001

Swarts, J. (2009). Recycled writing: Assembling actor networks from reusable content. Journal of Business and Technical Communication, 24(2), 127-163. https://doi.org/10.1177/1050651909353307

Wolfe, J. (2010). Team writing: A guide to working in groups. Boston, MA: Bedford-St. Martins. Zehner, B., \& Pletcher, G. (2017). Successful technology commercialization - Yes or no? Improving the odds. The quick look methodology and process. MINIB, 25(3), 81-102.

\title{
Address for correspondence
}

\author{
Eva-Maria Jakobs \\ RWTH Aachen University \\ Human-Computer Interaction Center \\ Text Linguistics and Technical Communication \\ Campus-Boulevard 57 \\ 52074 Aachen \\ Germany \\ e.m.jakobs@tk.rwth-aachen.de
}


Co-author information

Claas Digmayer

RWTH Aachen University

Human-Computer Interaction Center

Text Linguistics and Technical

Communication

c.digmayer@tk.rwth-aachen.de 